\title{
Immediate effect of intravitreal injection of bevacizumab on intraocular pressure
}

\author{
This article was published in the following Dove Press journal: \\ Clinical Ophthalmology \\ 23 July 2014 \\ Number of times this article has been viewed
}

\author{
Ricardo Lemos-Reis' \\ Nuno Moreira-Gonçalves' \\ António B Melo' \\ Ângela M Carneiro' ${ }^{1,2}$ \\ Fernando M Falcão-Reis ${ }^{1,2}$ \\ 'Department of Ophthalmology \\ of Hospital de São João, Porto, \\ Portugal; ${ }^{2}$ Department of Sense \\ Organs, Faculty of Medicine, \\ University of Porto, Porto, \\ Portugal
}

Correspondence: Ricardo Filipe da Silva Lemos-Reis

Hospital de São João,

Rua Dr Manuel Laranjeira número

I38, $5^{\circ}$ Frente, 4200-384 Paranhos,

Porto, Portugal

Tel +35I 916287988

Email r.lemosreis@gmail.com
Purpose: To investigate the immediate effect of intravitreal injection of bevacizumab on intraocular pressure (IOP).

Methods: This was a prospective and nonrandomized study. A total of 291 eyes with macular edema or active choroidal neovascularization were submitted to a single $1.25 \mathrm{mg}(0.05 \mathrm{~mL})$ bevacizumab intravitreal injection. Intraocular pressure was measured with an Icare ${ }^{\circledR}$ tonometer immediately before and after injection in a seated position. The presence of subconjunctival reflux was recorded. The fellow eye served as the control.

Results: Mean preoperative IOP was $18.0 \pm 5.9 \mathrm{mmHg}$ in the treated eye versus $16.9 \pm 6.0 \mathrm{mmHg}$ in the fellow eye. Mean postoperative IOP was $42.1 \pm 14.5 \mathrm{mmHg}$ in the treated eye versus $17.5 \pm 6.0 \mathrm{mmHg}$ in the fellow eye. The IOP variation was statistically significant in both cases and controls $(P<0.001$ and $P=0.003$, respectively), and this increase was higher in cases than in controls $(P<0.001)$. Postoperative IOPs higher than $50 \mathrm{mmHg}$ were achieved in $32.0 \%$ of the eyes. Subconjunctival reflux was present in $21.3 \%$ and determined a lower IOP rise $(P<0.001)$. Tested variables (glaucoma, phakic status, and sex) did not have a statistically significant effect on IOP rise or subconjunctival reflux.

Conclusion: IOP increases with intravitreal bevacizumab injection, reaching $50 \mathrm{mmHg}$ or more in about one third of patients. A higher IOP is expected if no subconjunctival reflux occurs. The baseline IOP does not influence the incidence of subconjunctival reflux. The clinical relevance of these facts has yet to be clarified.

Keywords: bevacizumab, intraocular pressure, intravitreal injection, Icare ${ }^{\mathbb{B}}$

\section{Introduction}

Intravitreal injection of antivascular endothelial growth factors (VEGF) has assumed a growing role in the treatment of several vitreoretinal diseases in the last few years.

Ranibizumab and aflibercept are the only approved anti-VEGF agents for the treatment of choroidal neovascularization resulting from age-related macular degeneration. ${ }^{1-3}$ In addition, ranibizumab has been approved for the treatment of macular edema associated with vein occlusion and diabetic macular edema. ${ }^{4,5}$ Despite this fact, the off-label use of bevacizumab (Avastin ${ }^{\circledR}$; Genentech, Inc., South San Francisco, CA, USA) for these ${ }^{6-8}$ and other ${ }^{9,10}$ entities has become globally widespread because of its low cost and similar results. ${ }^{11}$

Issues concerning safety with the intraocular use of these agents, particularly bevacizumab, are still being raised and widely discussed in scientific, managerial, and public circles. Ocular adverse effects are well known and include endophthalmitis, cataract, vitreous hemorrhage, retinal tear, and detachment. ${ }^{12}$ With regard to systemic adverse effects, bevacizumab and ranibizumab have been compared, with no significant difference found between the drugs in terms of rates of death or arteriothrombotic events. ${ }^{7}$ 
Given the addition of fluid into the vitreous cavity, an increase in intraocular pressure (IOP) should be expected after intravitreous anti-VEGF delivery. ${ }^{13-17}$ This is usually transient, but occasionally, it can persist. ${ }^{14,16-21}$ An acute IOP rise has been shown to decrease both optic nerve head and juxtapapillary retinal blood flow proportionally to the quantitative rise in IOP. ${ }^{22}$ The axonal transport to the optic nerve head has also been proved to be blocked by an acute IOP increase in animal models. ${ }^{23}$ Although the real consequences of these findings are not clear, possible ganglion cell loss cannot be underestimated, mostly in patients with previous glaucoma or other optic neuropathies.

This prospective study was meant to quantify the IOP rise that occurs immediately after intravitreal bevacizumab injection and to investigate potential risk factors associated with this rise.

\section{Methods}

A prospective and nonrandomized study of patients undergoing intravitreal injection of bevacizumab was conducted at the ophthalmology department of Hospital de São João in Oporto, Portugal, between June 1, 2011, and March 31, 2012. The study included patients who were at least 18 years of age and who had a diagnosis of active choroidal neovascularization or macular edema with clinical criteria for antiangiogenic treatment. Patients with previous ocular surgeries, with the exception of cataract surgery, or intravitreal injections of corticosteroids within the previous 3 months were excluded. Informed consent was obtained for each patient.

Intravitreal injections were given at the operating theater by 12 surgeons who were familiar with the procedure and used the same technique. In patients receiving unilateral anti-VEGF injections, the noninjected fellow eye served as a control.

Preoperative management was done according to our department's protocol for the procedure. Every patient undertook prophylaxis with topical ofloxacin $(3 \mathrm{mg} / \mathrm{mL})$ four times a day for 3 days before the procedure. The topical instillation of $0.5 \%$ tropicamide hydrochloride, $2.5 \%$ phenylephrine hydrochloride was also performed 20 minutes before the intravitreal injection. In the operating theater, in a seated position and immediately before the procedure, five valid IOP measurements were taken with the Icare ${ }^{\circledR}$ on both eyes. The mean IOP obtained by the instrument was recorded.

Patients were placed in a supine position, and after topical instillation of $0.4 \%$ oxybuprocaine hydrochloride, $5 \%$ povidone iodine was applied over the eyelids and in the conjunctival sac.
After lid speculum placement, the inferotemporal area of sclera to be injected was marked with a caliper measuring 3.5 or $4 \mathrm{~mm}$ from the surgical limbus, depending on whether the patient was pseudophakic or phakic, respectively. Using a 30-gauge needle on an insulin syringe, $0.05 \mathrm{~mL}(1.25 \mathrm{mg})$ bevacizumab was then injected through the pars plana into the vitreous cavity, using a nonbeveled incision technique. After injection, a sterile cotton swab was used to occlude and massage the injection site. Anterior chamber paracentesis was not performed in any case. The occurrence of subconjunctival reflux was recorded. Immediately after the procedure, the patient was placed in a seated position and IOP was measured and recorded bilaterally, using the already described method.

As soon as the IOP was measured, all patients were checked for hand motion vision at a distance of $50 \mathrm{~cm}$ with the noninjected eye occluded. Topical ofloxacin $(3 \mathrm{mg} / \mathrm{mL})$ was administered four times a day to all patients in the 5 days after the intravitreal injection.

All records from a computer database were reviewed, and the following additional data were collected: age, sex, history of glaucoma, phakic status, and vitreoretinal disease.

Data were analyzed using SPSS Statistics 17.0 (SPSS Inc., Chicago, IL, USA). Comparison between IOP before and after the procedure was made with paired Student's $t$-test. The difference in IOP increase, regarding the presence of reflux, previous history of glaucoma, and phakic state, was compared using the Mann-Whitney and Kruskal-Wallis tests. The chi-square test was used to study the odds of achieving an IOP spike (defined by the authors as an IOP value above $50 \mathrm{mmHg}$ ) after injection, as well as the odds of occurrence of subconjunctival reflux.

\section{Results}

We included 291 eyes of 291 patients. The mean age was 75 years (ranging from 35-95 years), with $64.3 \%$ of the patients being women. One hundred seventy-one eyes were phakic, 114 were pseudophakic, and 6 were aphakic. Twentyseven patients had previous history of glaucoma (Table 1). The most common reason for injection of bevacizumab was neovascular age-related macular degeneration (72.9\%), followed by choroidal neovascularization secondary to pathological myopia (9.6\%) (Figure 1).

Subconjunctival reflux was noticed in $21.3 \%$ of the procedures.

Treated eyes had a mean IOP before injection of $18.0 \pm 5.9 \mathrm{mmHg}$; after injection it was $42.1 \pm 14.5 \mathrm{mmHg}$ $(P<0.001)$. The mean rise of IOP was $28.6 \pm 13.8 \mathrm{mmHg}$ (range, $0-69 \mathrm{mmHg}$ ) in the absence of reflux and $7.7 \pm 10.3 \mathrm{mmHg}$ 
Table I Patients' demographics and characteristics

\begin{tabular}{lll}
\hline Characteristics & Frequency, $\mathbf{~}$ & Percentage \\
\hline $\begin{array}{l}\text { Age, mean } \\
\text { Injected eye }\end{array}$ & $75.40 \pm 12.17$ & \\
OD & 148 & 50.9 \\
OS & 143 & 49.1 \\
Sex & & \\
$\quad$ Male & 104 & 35.7 \\
Female & 187 & 64.3 \\
Glaucoma & & \\
Present & 27 & 9.3 \\
$\quad$ Absent & 264 & 90.7 \\
Phakic status & & \\
Phakic & $17 \mid$ & 58.8 \\
Pseudophakic & 114 & 39.2 \\
Aphakic & 6 & 2.0 \\
\hline
\end{tabular}

Abbreviations: OD, right eye; OS, left eye.

(range, -18 to $34 \mathrm{mmHg}$ ) in the presence of reflux $(P<0.001)$. In control eyes, the mean IOP before injection was $16.9 \pm 6.0 \mathrm{mmHg}$, and after injection, it was $17.5 \pm 6.0 \mathrm{mmHg}$. This difference was statistically significant $(P=0.003)$.

Regarding previous history of glaucoma, the difference in the amount of IOP rise was not statistically significant (20.7 $\mathrm{mmHg}$ in patients with glaucoma history versus $24.5 \mathrm{mmHg}$ in patients without glaucoma history; $P=0.18$ ). The same was noted when comparing phakic with pseudophakic eyes (24.4 and $24.2 \mathrm{mmHg}$, respectively; $P=0.90$ ).

None of the studied variables showed a statistically significant influence in obtaining a postinjection IOP spike (Table 2), which occurred in $32.0 \%$ of the procedures. Regarding patients with glaucoma history, the odds ratio (OR) was 0.53 ( $95 \%$ confidence interval $[\mathrm{CI}], 0.19-1.15 ; P=0.23$ ). Comparing phakic eyes with pseudophakic or aphakic eyes, the OR was 1.28 (95\% CI, 0.74-2.22; $P=0.59)$. Male patients had an OR of 1.16 (95\% CI, 0.67-2.01; $P=0.37)$.

When studying the odds of subconjunctival reflux occurrence, none of the potential risk factors studied reached statistical significance (Table 2). For patients with glaucoma history, the OR was 0.94 (95\% CI, 0.33-2.67; $P=0.90)$. Phakic eyes had an OR of 1.15 (95\% CI, 0.61-2.18; $P=0.67)$. Male patients had an OR of 0.72 (95\% CI, 0.38-1.36; $P=0.31$ ).

\section{Discussion}

The intravitreal injection of antiangiogenic agents has assumed, globally, a leading role in the treatment of a growing number of ophthalmologic conditions since 2005, when the intravitreal use of bevacizumab was first reported. ${ }^{18,21,24-26} \mathrm{An}$ increase in IOP after this procedure is expected, and therefore issues regarding its safety, the necessity of IOP monitoring, and possible implications for operating theater dynamics have been raised.

The 291 patients enrolled in this study showed a mean IOP rise of $24.1 \mathrm{mmHg}$, with a final average IOP of $42.1 \mathrm{mmHg}$ immediately after the intravitreal injection of bevacizumab. These results have been shown to be statistically significant when matched with the baseline IOP and with the IOP rise that obtained in the noninjected eyes. Kim et $\mathrm{al}^{15}$ investigated the short-term IOP changes immediately after intravitreal injection of anti-VEGF and found a higher mean IOP change of $30 \mathrm{mmHg}$ from baseline. However, in addition to bevacizumab, Kim et al also included other drugs in their study (namely, triamcinolone and ranibizumab) and different needle sizes (27, 30, and 32 gauge), which may explain this difference. All other previous studies on the same subject started their IOP measurements between 2 and 30 minutes after injection, ${ }^{13,14,16}$ therefore precluding any accurate comparisons with the present study that aimed to measure the IOP peak that occurs immediately after the injection.

Despite there being no injection made, a mean IOP rise of $0.6 \mathrm{mmHg}$ was also noted and found to be significant in the control group. As previously reported, changes in body position are correlated to IOP variation, with higher readings seen in a supine versus a seated position. ${ }^{27-30}$ In addition, the increase in IOP when a supine position is assumed has been reported to be caused not only by the increase in episcleral venous pressure ${ }^{27-30}$ but also by other unknown factors. ${ }^{30}$ Given this, a possible explanation for the IOP rise in noninjected eyes might rely on the short period of time between the change from a supine to a seated position and the respective IOP reading. This was probably insufficient for the hydrostatic changes to occur and for the episcleral

Table 2 Risk factors for intraocular pressure higher than $50 \mathrm{mmHg}$ and subconjunctival reflux

\begin{tabular}{|c|c|c|}
\hline Risk factors & $\begin{array}{l}\text { Intraocular pressure higher } \\
\text { than } 50 \mathrm{mmHg} \text {, odds ratio } \\
\text { (95\% confidence interval) }\end{array}$ & $\begin{array}{l}\text { Subconjunctival reflux, odds } \\
\text { ratio ( } 95 \% \text { confidence interval) }\end{array}$ \\
\hline Male sex & $1.16(0.67-2.01)$ & $0.72(0.38-1.36)$ \\
\hline Phakic status & $1.28(0.74-2.22)$ & I.I5 (0.6I-2.18) \\
\hline Glaucoma history & $0.53(0.19-1.15)$ & $0.94(0.33-2.67)$ \\
\hline
\end{tabular}




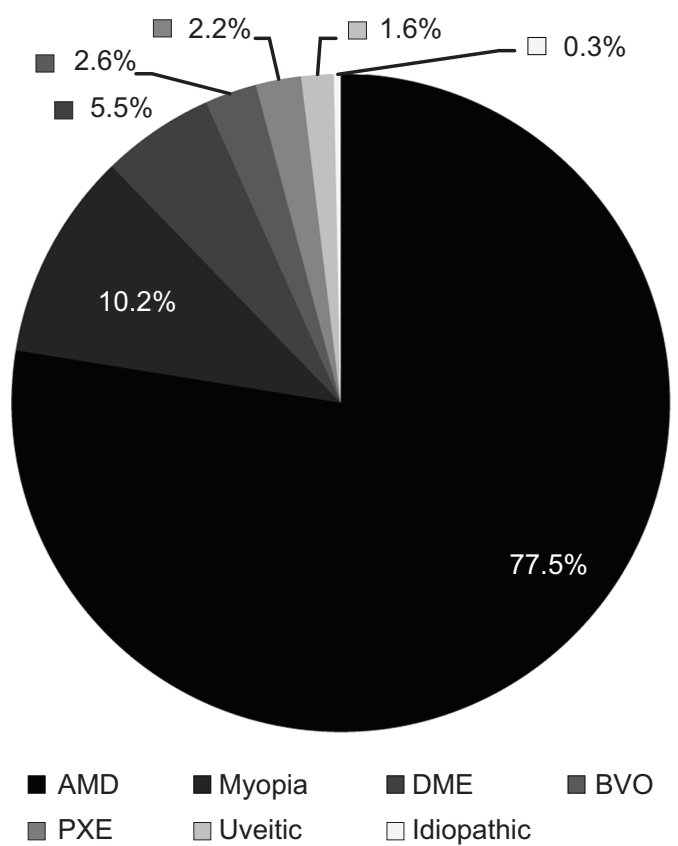

Figure I Vitreoretinal disease distribution.

Abbreviations: AMD, exudative age macular degeneration; myopia, myopic choroidal neovascularization; DME, diabetic macular edema; PXE, pseudoxanthoma elasticum; BVO, branch retinal vein occlusion; uveitic, uveitic choroidal neovascularization; idiopathic, idiopathic choroidal neovascularization.

venous pressure to settle. Although statistical significance was achieved, no clinical relevance seems to exist.

The IOP spike that occurs after the intravitreal injection of bevacizumab is usually transient, with IOP returning to a safer range $(<25-30 \mathrm{mmHg})$ within 15 to 30 minutes, without a paracentesis or glaucoma medications, in most patients. ${ }^{13-16}$ Therefore, and in the absence of complications, hand motion vision and optic disk perfusion assessment were suggested by Kim et $\mathrm{al}^{15}$ as an alternative to prolonged IOP monitoring. Considering this, every patient in this study was tested successfully for hand movement vision. However, because of operating theater dynamics, the optic disk perfusion was not checked, which is a safety limitation. The decision whether to monitor or treat IOP spikes was left to the surgeon and his or her clinical judgment.

Several reports on persistent ocular hypertension (OHT) after intravitreal injection of anti-VEGF exist, with prevalence rates ranging between $1.7 \%$ and $11 \% .{ }^{18-20,31}$ Mathalone et $\mathrm{al}^{20}$ described a shorter interval between injections ( $<8$ weeks) as a risk factor for sustained OHT on wet agerelated macular degeneration. Adelman et al ${ }^{18}$ suggested that the prevalence of OHT could be linked to the number of injections. Hoang et $\mathrm{al}^{17}$ found that an increased risk for IOP elevation higher than $5 \mathrm{mmHg}$ on two or more consecutive visits existed when comparing patients receiving 29 or more injections and those receiving 12 or fewer injections.
In this study, $32 \%$ of the patients had a postinjection IOP spike. This acute rise can induce damage to the optic nerve head by compromising its autoregulatory mechanisms ${ }^{32}$ and change the lamina cribrosa contour. ${ }^{33}$ An IOP spike was reported by Kim et $\mathrm{al}^{15}$ in $36 \%$ of cases. Hollands et $\mathrm{al}^{14}$ found it in $10 \%$ of the patients 2 minutes after intravitreal injection, which gives additional proof and support to the transient nature of this rise.

Despite the true long-term consequences of these extreme IOP elevations not being known, one should not underestimate their intrinsic deleterious potential, mainly in patients with glaucoma or other optic neuropathies. The possibility of using a postoperative paracentesis or topical pressurelowering medications as prophylaxis should be considered. $\mathrm{El}$ Chehab et $\mathrm{al}^{19}$ have found that the prophylactic use of a fixed combination of timolol and brimonidine or dorzolamide and the single use of $1 \%$ apraclonidine could reduce the IOP spikes and their duration. The use of $250 \mathrm{mg}$ acetazolamide 20 minutes before the intravitreal injection, however, has been proved to be ineffective.

None of the tested variables (history of glaucoma, male sex, and phakic status) previously suggested as possible risk factors for higher and more sustained OHT has proved to have a statistically significant effect on postinjection IOP in this study. ${ }^{15,16,20}$ This study, however, did not aim to evaluate the sustainability of OHT but addressed only the acute rise in pressure. In contrast, only 30 patients had a history of glaucoma; this small sample may explain the absence of a statistical effect of this variable on IOP spikes.

Subconjunctival reflux was reported in about a quarter of the patients and led to a lower IOP increase. This has proved to be significant when compared with the IOP rise in patients without this event. Lorenz et $\mathrm{al}^{34}$ reported reflux in $52.9 \%$ of cases using 30-gauge needles and concluded that there was a direct relationship between needle thickness and reflux grade and an inverse relationship between needle thickness and the frequency of paracentesis for acute reduction of the IOP. This higher reflux rate may be explained by the low threshold used by the authors when reporting subconjunctival reflux. When the eyes with reflux rate graded as $1(0.01 \mathrm{~mL})$ are withdrawn, their reflux rate falls to $21.7 \%$, which is similar to our results. The amount of reflux is influenced by the incision technique, being lower with a beveled approach, ${ }^{35}$ in contrast to the nonbeveled approach in our study. The reflux rate may also be lower in some centers with the preoperative use of the Honan intraocular pressure reducer. ${ }^{36}$ This study did not quantify the reflux, which is an obvious limitation. 
Neither of the studied variables were proved to have influence on the subconjunctival reflux rate. The small number of glaucoma patients in the study was, again, a statistical bias.

To the best of our knowledge, this is the largest prospective study performed evaluating the immediate effect of intravitreal injection of bevacizumab on IOP and the first study on this topic using the Icare ${ }^{\circledR}$ tonometer to measure intraocular pressures, which may limit any comparisons done with other published studies on the subject. The rebound tonometer shows a good correlation with the Goldmann applanation tonometer. ${ }^{37-40}$ However, central corneal thickness influences this agreement (overestimation of IOP with the Icare ${ }^{\circledR}$ tonometer) ${ }^{37}$ Some authors claim this correlation is affected by the IOP range, being less reliable for higher values, ${ }^{38}$ whereas others state the opposite. ${ }^{39}$ The Icare $^{\circledR}$ tonometer is a portable, comfortable, and reliable solution $^{39}$ to monitoring IOP and therefore seemed a suitable solution for operating theater environment use by the authors.

In conclusion, intravitreal injection of bevacizumab may induce a significant rise in IOP. Spikes of more than $50 \mathrm{mmHg}$ may occur in about one third of the cases, which can cause damage to the optic nerve. Prevention of these pressure spikes should be considered not only in patients showing previous optic nerve damage, namely, those with advanced glaucoma, but also in patients with a history of multiple injections. To substantiate this opinion, however, additional studies addressing the possible loss of retinal ganglion cells with repeated intravitreal injections are needed.

\section{Acknowledgment}

We thank all colleagues who participated in the operating theater performing measurements of IOP.

\section{Disclosure}

The authors report no conflicts of interest in this work.

\section{References}

1. Rosenfeld PJ, Brown DM, Heier JS, et al; MARINA Study Group. Ranibizumab for neovascular age-related macular degeneration. $N$ Engl J Med. 2006;355(14):1419-1431.

2. Brown DM, Kaiser PK, Michels M, et al; ANCHOR Study Group. Ranibizumab versus verteporfin for neovascular age-related macular degeneration. N Engl J Med. 2006;355(14):1432-1444.

3. Heier JS, Brown DM, Chong V, et al; VIEW 1 and VIEW 2 Study Groups. Intravitreal aflibercept (VEGF trap-eye) in wet age-related macular degeneration. Ophthalmology. 2012;119(12):2537-2548.

4. Mitchell P, Bandello F, Schmidt-Erfurth U, et al; RESTORE study group. The RESTORE study: ranibizumab monotherapy or combined with laser versus laser monotherapy for diabetic macular edema. Ophthalmology. 2011;118(4):615-625.
5. Nguyen QD, Brown DM, Marcus DM, et al; RISE and RIDE Research Group. Ranibizumab for diabetic macular edema: results from 2 phase III randomized trials: RISE and RIDE. Ophthalmology. 2012;119(4):789-801.

6. Rajendram R, Fraser-Bell S, Kaines A, et al. A 2-year prospective randomized controlled trial of intravitreal bevacizumab or laser therapy (BOLT) in the management of diabetic macular edema: 24-month data: report 3. Arch Ophthalmol. 2012;130(8):972-979.

7. Martin DF, Maguire MG, Fine SL, et al; Comparison of Age-related Macular Degeneration Treatments Trials (CATT) Research Group. Ranibizumab and bevacizumab for treatment of neovascular age-related macular degeneration: two-year results. Ophthalmology. 2012;119(7): $1388-1398$.

8. Ford JA, Elders A, Shyangdan D, Royle P, Waugh N. The relative clinical effectiveness of ranibizumab and bevacizumab in diabetic macular oedema: an indirect comparison in a systematic review. $B M J$. 2012;345(aug13 1):e5182.

9. Bae JH, Lee CS, Lee SC. Efficacy and safety of intravitreal bevacizumab compared with intravitreal and posterior sub-tenon triamcinolone acetonide for treatment of uveitic cystoid macular edema. Retina. 2011;31(1): 111-118.

10. Mayer WJ, Remy M, Wolf A, et al. Comparison of intravitreal bevacizumab upload followed by a dexamethasone implant versus dexamethasone implant monotherapy for retinal vein occlusion with macular edema. Ophthalmologica. 2012;228(2):110-116.

11. Smiddy WE. Economic implications of current age-related macular degeneration treatments. Ophthalmology. 2009;116(3):481-487.

12. Fung $A E$, Rosenfeld $P J$, Reichel $E$. The International Intravitreal Bevacizumab Safety Survey: using the internet to assess drug safety worldwide. Br J Ophthalmol. 2006;90(11):1344-1349.

13. Falkenstein IA, Cheng L, Freeman WR. Changes of intraocular pressure after intravitreal injection of bevacizumab (avastin). Retina. 2007;27(8): 1044-1047.

14. Hollands H, Wong J, Bruen R, Campbell RJ, Sharma S, Gale J. Short-term intraocular pressure changes after intravitreal injection of bevacizumab. Can J Ophthalmol. 2007;42(6):807-811.

15. Kim JE, Mantravadi AV, Hur EY, Covert DJ. Short-term intraocular pressure changes immediately after intravitreal injections of anti-vascular endothelial growth factor agents. Am J Ophthalmol. 2008;146(6): 930-934.e1.

16. Bakri SJ, Pulido JS, McCannel CA, Hodge DO, Diehl N, Hillemeier J. Immediate intraocular pressure changes following intravitreal injections of triamcinolone, pegaptanib, and bevacizumab. Eye (Lond). 2009;23(1):181-185.

17. Hoang QV, Mendonca LS, Della Torre KE, Jung JJ, Tsuang AJ, Freund KB. Effect on intraocular pressure in patients receiving unilateral intravitreal anti-vascular endothelial growth factor injections. Ophthalmology. 2012;119(2):321-326.

18. Adelman RA, Zheng Q, Mayer HR. Persistent ocular hypertension following intravitreal bevacizumab and ranibizumab injections. J Ocul Pharmacol Ther. 2010;26(1):105-110.

19. El Chehab H, Le Corre A, Agard E, et al. Effect of topical pressurelowering medication on prevention of intraocular pressure spikes after intravitreal injection. Eur J Ophthalmol. Epub 2012 Nov 15.

20. Mathalone N, Arodi-Golan A, Sar S, et al. Sustained elevation of intraocular pressure after intravitreal injections of bevacizumab in eyes with neovascular age-related macular degeneration. Graefes Arch Clin Exp Ophthalmol. 2012;250(10):1435-1440.

21. Wehrli SJ, Tawse K, Levin MH, Zaidi A, Pistilli M, Brucker AJ. A lack of delayed intraocular pressure elevation in patients treated with intravitreal injection of bevacizumab and ranibizumab. Retina. 2012;32(7): 1295-1301.

22. Michelson G, Groh MJ, Langhans M. Perfusion of the juxtapapillary retina and optic nerve head in acute ocular hypertension. Ger J Ophthalmol. 1996;5(6):315-321.

23. Quigley HA, Anderson DR. Distribution of axonal transport blockade by acute intraocular pressure elevation in the primate optic nerve head. Invest Ophthalmol Vis Sci. 1977;16(7):640-644. 
24. Rosenfeld PJ, Moshfeghi AA, Puliafito CA. Optical coherence tomography findings after an intravitreal injection of bevacizumab (avastin) for neovascular age-related macular degeneration. Ophthalmic Surg Lasers Imaging. 2005;36(4):331-335.

25. Avery RL, Pieramici DJ, Rabena MD, Castellarin AA, Nasir MA, Giust MJ. Intravitreal bevacizumab (Avastin) for neovascular age-related macular degeneration. Ophthalmology. 2006;113(3): 363-372.e5.

26. Algvere PV, Steén B, Seregard S, Kvanta A. A prospective study on intravitreal bevacizumab (Avastin) for neovascular age-related macular degeneration of different durations. Acta Ophthalmol (Copenh). 2008; 86(5):482-489.

27. Kaskel D, Müller-Breitenkamp R, Wilmans I, Rudolf H, Jessen K. Augeninnendruck, Episkleralvenendruck und Blutdruck bei Anderung der Körperlage. Albrecht Von Graefes Arch Klin Exp Ophthalmol. 1978; 208(4):217-228. German.

28. Liu JH, Kripke DF, Twa MD, et al. Twenty-four-hour pattern of intraocular pressure in the aging population. Invest Ophthalmol Vis Sci. 1999;40(12):2912-2917.

29. Prata TS, De Moraes CG, Kanadani FN, Ritch R, Paranhos A Jr. Posture-induced intraocular pressure changes: considerations regarding body position in glaucoma patients. Surv Ophthalmol. 2010;55(5):445-453.

30. Lam AK, Douthwaite WA. Does the change of anterior chamber depth or/and episcleral venous pressure cause intraocular pressure change in postural variation? Optom Vis Sci. 1997;74(8):664-667.

31. Choi DY, Ortube MC, McCannel CA, et al. Sustained elevated intraocular pressures after intravitreal injection of bevacizumab, ranibizumab, and pegaptanib. Retina. 2011;31(6):1028-1035.
32. Riva CE, Hero M, Titze P, Petrig B. Autoregulation of human optic nerve head blood flow in response to acute changes in ocular perfusion pressure. Graefes Arch Clin Exp Ophthalmol. 1997;235(10):618-626.

33. Yan DB, Coloma FM, Metheetrairut A, Trope GE, Heathcote JG, Ethier CR. Deformation of the lamina cribrosa by elevated intraocular pressure. Br J Ophthalmol. 1994;78(8):643-648.

34. Lorenz K, Zwiener I, Mirshahi A. Subconjunctival reflux and need for paracentesis after intravitreal injection of $0.1 \mathrm{~mL}$ bevacizumab: comparison between 27-gauge and 30-gauge needle. Graefes Arch Clin Exp Ophthalmol. 2010;248(11):1573-1577.

35. Rodrigues EB, Grumann A Jr, Penha FM, et al. Effect of needle type and injection technique on pain level and vitreal reflux in intravitreal injection. J Ocul Pharmacol Ther. 2011;27(2):197-203.

36. Hong SW, Jee D. Effect of the Honan intraocular pressure reducer to prevent vitreous reflux after intravitreal bevacizumab injection. Eur $J$ Ophthalmol. 2012;22(4):615-619.

37. Nakamura M, Darhad U, Tatsumi Y, et al. Agreement of rebound tonometer in measuring intraocular pressure with three types of applanation tonometers. Am J Ophthalmol. 2006;142(2):332-334.

38. Munkwitz S, Elkarmouty A, Hoffmann EM, Pfeiffer N, Thieme H. Comparison of the iCare rebound tonometer and the Goldmann applanation tonometer over a wide IOP range. Graefes Arch Clin Exp Ophthalmol. 2008;246(6):875-879.

39. Pakrou N, Gray T, Mills R, Landers J, Craig J. Clinical comparison of the Icare tonometer and Goldmann applanation tonometry. J Glaucoma. 2008;17(1):43-47.

40. Scuderi GL, Cascone NC, Regine F, Perdicchi A, Cerulli A, Recupero SM. Validity and limits of the rebound tonometer (ICare ${ }^{\circledR}$ ): clinical study. Eur J Ophthalmol. 2011;21(3):251-257.
Clinical Ophthalmology

\section{Publish your work in this journal}

Clinical Ophthalmology is an international, peer-reviewed journal covering all subspecialties within ophthalmology. Key topics include: Optometry; Visual science; Pharmacology and drug therapy in eye diseases; Basic Sciences; Primary and Secondary eye care; Patient Safety and Quality of Care Improvements. This journal is indexed on

\section{Dovepress}

PubMed Central and CAS, and is the official journal of The Society of Clinical Ophthalmology (SCO). The manuscript management system is completely online and includes a very quick and fair peer-review system, which is all easy to use. Visit http://www.dovepress.com/ testimonials.php to read real quotes from published authors. 